\title{
A UTILIZAÇÃO DA ARBITRAGEM NOS DISSÍDIOS INDIVIDUAIS TRABALHISTAS: UMA ANÁLISE FRENTE AO EMPREGADO PARASSUBORDINADO
}

\author{
THE USE OF ARBITRATION IN INDIVIDUAL LABOR LAWSUIT: AN ANALYSIS \\ TOWARDS PARASUBORDINATI EMPLOYEE
}

\author{
${ }^{1}$ Italo Moreira Reis \\ ${ }^{2}$ Neuber Teixeira dos Reis Junior
}

\begin{abstract}
RESUMO
O presente artigo tem por objeto a análise circunstancial da viabilidade de utilização da arbitragem, como método alternativo de solução de conflitos, nos dissídios individuais trabalhistas, quando se tratar de empregado parassubordinado. Cumpre mencionar que no panorama legal nacional não há regulação específica sobre o trabalhador parassubordinado, fato que pode vir a servir como impedimento para o reconhecimento, de plano, da relação empregatícia entre este e o seu tomador de serviço. Não se olvida a presença de uma autonomia maior nas relações laborais que envolvam os empregados parassubordinados em relação aos tradicionais contratos de emprego. Contudo, após uma detida apreciação sobre a evolução do conceito clássico da subordinação, atentando-se para uma análise interpretativa sistemático-teleológica, torna-se clara a existência dos elementos fáticos jurídicos do contrato de emprego. Neste cenário, e com base na literatura sobre o tema, tem-se que não obstante o entendimento majoritário quanto à impossibilidade de se utilizar a arbitragem no tratamento de questões trabalhistas provenientes dos contratos individuais do trabalho- seja pela hipossuficiência do trabalhador seja pela indisponibilidade dos direitos trabalhistas- traz-se à baila a necessidade de se discutir sobre o amadurecimento da utilização do referido instituto quando se tratar de direitos individuais laborais, principalmente, quando se denota a presença de empregados parassubordinados, que, comparados com os demais, possuem uma maior autonomia na realização de seus serviços e uma substancial redução de hipossuficiência frente ao seu empregador. A metodologia utilizada é eminentemente de cunho teóricodogmático, através de pesquisa da bibliografia sobre o tema, além da necessária consulta à jurisprudência dos tribunais trabalhistas.
\end{abstract}

Palavras-chave: Subordinação, Arbitragem, Parassubordinação

\footnotetext{
${ }^{1}$ Mestre em Direito do Trabalho, Modernidade e Democracia pela Pontifícia Universidade Católica -PUC, Belo Horizonte, Minas Gerais, (Brasil). Professor nos Cursos de Pós Graduação lato Sensu, Instituto Elpídio Donizetti IED, Belo Horizonte, Minas Gerais. E-mail: tutortreinamento@gmail.com

${ }^{2}$ Especialização em Andamento em Gestão Pública Judicial pela Universidade Federal de Ouro Preto - UFOP, Ouro Preto, Minas Gerais, (Brasil). Professor da Faculdades Instituto Doctum de Educação e Tecnologia, DOCTUM. Email: tutortreinamento@gmail.com
} 


\begin{abstract}
This article focuses on the circumstantial examination of the feasibility of using arbitration as an alternative method of conflict resolution in labor individual bargaining, in the case of parasubordinati employee. It should be mentioned that in Brazilian Law there is no specific regulation on the parasubordinati worker, which may come to serve as an impediment to recognition, plan, the employment relationship between it and your service borrower. Do not forgets the presence of greater autonomy in labor relations involving this kind of employees over traditional employment contracts. However, after a detained assessment of the evolution of the classical concept of subordination, paying attention to one systematic-teleological interpretative analysis, it becomes clear the existence of the legal factual elements of the employment contract. In this way, although that despite the prevailing understanding as to the impossibility of using arbitration in the treatment of labor issues from the individual employment contracts, whether by worker hypo-sufficient is the unavailability of labor rights, brings to the fore the need to discuss about the maturation of the use of such institute in the case of individual labor rights, especially when it denotes the presence of parasubordinati employees, which, compared with others, have greater autonomy in carrying out their services and a substantial reduction hypo-sufficient front of his employer. The methodology used is eminently theoretical-dogmatic nature, through searching the literature on the theme, beyond the necessary consultation of the jurisprudence of labor courts.
\end{abstract}

Keywords: Subordination, Arbitration, Parasubordinazione 


\section{INTRODUÇÃO}

As inúmeras reformas jurídicas ao longo dos anos, inclusive com a recente promulgação de um Novo Código de Processo Civil ${ }^{1}$, são fatores que, por si só, não se mostraram (ão), suficientes para a concretização da garantia constitucional da razoável duração do processo.

Permanece instaurada, na sociedade brasileira, a cultura do litígio, que abarrota cada dia mais o Poder Judiciário, desmantelando, por consequência, a credibilidade desta instituição, tendo em vista a morosidade e a ineficiência para a entrega do direito material vindicado pelo sujeito que o tenha por direito.

A utilização do instituto da arbitragem, no âmbito do direito do trabalho individual, encontra grande resistência por parte da doutrina e da jurisprudência especializada. Uma das formas de se enfrentar, com prudência, tal receio, é a aplicação de tal método nas demandas em que forem partes o empregador e o empregado parassubordinado. Isto porque este tipo de trabalhador possui maior autonomia na prestação de seus serviços, mormente por exercer cargos de chefia e grande gestão, existindo, desse modo, uma redução da hipossuficiência quando comparado ao empregado tradicional.

Reconhecido este cenário, revela-se imprescindível atentar-se para os benefícios oriundos da utilização de métodos alternativos a resolução de conflitos, em especial à arbitragem, em que um terceiro, de modo imparcial, deverá julgar o conflito, de forma célere e eficaz, valendo tal decisão como título executivo judicial, exigível perante o órgão jurisdicional competente.

A pesquisa é justificada pela crescente preocupação na implementação de medidas que visem à redução do número de ações judiciais, através da utilização de soluções alternativas de conflito.

Justifica-se, outrossim, por se tratar de tema ainda pouco difundido doutrinariamente na seara trabalhista, sendo que, para se solidificar um novo posicionamento no que concerne a possibilidade de utilização da via arbitral nos dissídios individuais laborais faz-se necessário engendrar as benesses deste método de composição desde que, evidentemente, respeitadas as nuances do contrato jus laboral.

A Lei $\mathrm{n}^{\circ} 13.105$, de 16 de março de 2015, entrará em vigor a partir de 16 de março de 2016, observado o período de vacatio legis de 1 (um) ano. 
Além da presente introdução, o artigo foi desenvolvido em outros três tópicos. No primeiro deles buscou-se analisar a evolução histórica da subordinação no âmbito jus laboral, a partir do que foi possível verificar a abordagem contemporânea desse instituto jurídico.

No segundo tópico demonstra-se a origem do conceito de parassubordinação e sua aplicação no que diz respeito às relações de trabalho.

Já no terceiro tópico discorre-se sobre a (im) possibilidade da aplicabilidade da arbitragem como método de resolução de conflitos que envolvem a relação entre empregadores e empregados parassubordinados.

Ao final, conclui-se pela viabilidade da utilização da arbitragem como método alternativo de resolução de conflitos individuais trabalhistas, nas lides envolvendo empregados parassubordinados, de modo a concretizar os interesses manifestado expressamente pelas partes envolvidas, de forma célere e desburocratizada.

\section{1 - EVOLUÇÃO HISTÓRICA DO CONCEITO DE SUBORDINAÇÃO NO DIREITO DO TRABALHO}

O Direito do Trabalho tem seu surgimento atrelado ao desenvolvimento do sistema de produção capitalista e à Revolução Industrial e emerge com a proposta de trazer equilíbrio à relação antinômica existente entre capital e trabalho.

A relação empregatícia, principal categoria socioeconômica sobre a qual incide o Direito do Trabalho, começou a se estruturar já no desenrolar da Revolução Industrial, num processo que se deu no final do século XVII e início do século XVIII, quando, de fato, a ruptura com o paradigma servil e escravocrata tornou-se generalizada.

A subordinação marca a transição do trabalho fundado na sujeição pessoal do trabalhador para o trabalho livre, no qual o trabalhador não mais se confunde com os meios de produção do empregador e torna-se autônomo em relação a estes, submetendo-se, contudo, a um rígido controle sobre o modo de prestação do serviço pactuado.

A princípio, o trabalhador contratado pelas fábricas possuía "modus operandi" de seu trabalho determinado pelo ritmo repetitivo e célere da máquina, num período marcado pelo rigoroso controle sobre o tempo de trabalho negociado com o empregador e modo de prestação do serviço. Esse controle exacerbado sobre o trabalho, inicialmente representado pela máquina, ganhou novos elementos ao longo dos anos. Michelle Perrot, em sua obra "Os Excluídos da História: operários, mulheres e prisioneiros” expõe a evolução do paradigma vigilante presente nas fábricas francesas em meados do século XIX: 


\begin{abstract}
"Os regulamentos se multiplicam ao longo do século XIX. Toda fábrica com alguma importância tem o seu, mais ou menos inspirado em modelos correntes. Relativamente simples e sucintos no início do século, eles se alongam e se especificam; o regulamento da Companhia das Forjas de Champagne de Saint-Dizier tem mais de sessenta artigos, o da Indústria Têxtil (Roubaix-Tourcoing,1900) comporta 167 deles! No começo, os regulamentos fixam os horários e o valor das multas; incluem sobretudo prescrições morais.” (1988, p.67-68)
\end{abstract}

Aquilo que pode ser entendido como uma verdadeira "era da disciplina" nas fábricas desenvolveu-se ainda mais e a disciplina personificou-se na figura do contramestre que, não obstante o típico papel de vigilância, nas palavras de Michele Perrot, possuía uma segunda função:

\footnotetext{
"Por outro lado, o contramestre tem uma função técnica crescente; ele deve vigiar e muitas vezes regular as máquinas, e com isso insinua-se pessoalmente no processo de produção que assim escapa aos trabalhadores. O contramestre pode regular até o ritmo de trabalho pela máquina" (1988, p.70)
}

É nesse contexto histórico, no auge do controle e da vigilância no mundo do trabalho que, progressivamente, se consolidava a figura do trabalhador que o Direito do Trabalho centrou-se em tutelar e maturava-se, concomitantemente, o que hoje entendemos por subordinação clássica.

No entanto, diante da complexidade das relações trabalhistas estabelecidas na contemporaneidade e das necessidades impostas pelo capitalismo, houve declínio do modelo de disciplina anteriormente empregado no mundo do trabalho.

O perfil do operariado comum não mais representa a grande massa de trabalhadores da atualidade e o rígido conceito de subordinação clássica tem se mostrado insuficiente para a caracterização das modernas relações de emprego.

Diversos questionamentos sobre o que, outrora, se entendia por subordinação surgiram na doutrina, sempre atenta à necessidade de o Direito do Trabalho expandir a sua protetividade ao trabalhador, permitindo que novos conceitos ganhassem força no ramo justrabalhista, quais sejam: subordinação estrutural, subordinação objetiva, subordinação estrutural-reticular e, por fim, aquela que será objeto de maior análise pelo presente artigo, a parassubordinação.

\title{
1.1 - As Dimensões do Conceito de Subordinação na Contemporaneidade
}


A subordinação, tomada em seu sentido clássico, é encarada sob uma perspectiva objetiva, recaindo não sobre o trabalhador, mas sobre a forma de prestação do serviço, oriunda da direção empresarial que o obreiro se compromete a acolher. A subordinação clássica, como preleciona Delgado: "Manifesta-se pela intensidade de ordens do tomador de serviços sobre o respectivo trabalhador" (2014, p.283), subsistindo na maior parte dos vínculos empregatícios.

Perante a organicidade da realidade, do aspecto elástico e inovador do Direito Empresarial e da inevitável influência destes no âmbito juslaboral, cabe à doutrina e jurisprudência trabalhista corresponderem, na mesma medida, aos desafios postos pela sociedade, preservando o papel social que cumpre o Direito do Trabalho. A subordinação estrutural, cunhada por Maurício Godinho Delgado, surge como resposta aos novos desafios do universo trabalhista, notadamente, a terceirização.

A subordinação estrutural é entendida como aquela em que o trabalhador, independentemente de tomar ou não ordens diretas do tomador de serviços, participa da dinâmica de funcionamento do empreendimento. Conforme Delgado:

\footnotetext{
"Nesta dimensão da subordinação, não importa que o trabalhador se harmonize(ou não) aos objetivos do empreendimento, nem que receba ordens diretas das específicas cheias deste: o fundamental é que esteja estruturalmente vinculado à dinâmica operativa da atividade do tomador de serviços.” (2014, p. 284)
}

Estrutural-reticular é a subordinação que trata daquelas relações em que há fusão de diversas empresas e tomadores de serviços, sendo que cada uma delas assume papel na direção da atividade laborativa. O pressuposto de tal subordinação vai além de seu aspecto jurídico abarcando também o aspecto econômico. De acordo com definição dada por José Eduardo de Resende Chaves Júnior e Marcus Menezes Barberino Mendes, criadores do conceito de subordinação estrutural-reticular:

\footnotetext{
“Com o conceito de subordinação estrutural-reticular apreende-se o fenômeno das coalizões de empresas e de empregadores, quer assumam formas jurídicas explícitas e reguladas pelo direito empresarial, quer sejam coalizões factuais, reconhecendo a possibilidade de que tais empresas ou empregadores assumam cada um parte das funções diretivas que o artigo $2^{\circ}$ da CLT estabelece como necessárias e suficientes ao reconhecimento do(s) sujeito(s) de deveres jurídicos do tomador.” (2008, p.3).
}

Outra vertente do instituto, a subordinação objetiva, por sua vez, é caracterizada pela inserção do trabalhador naquelas atividades consideradas fins, objetivos do empreendimento. 
Portanto, mesmo que a direção do tomador de serviços ocorra de forma menos intensa, não estará descaracterizado o vínculo empregatício caso o obreiro, submetido ao poder jurídico do empregador sobre o seu trabalho, integre as finalidades do empreendimento.

\section{2 - PARASSUbordinaÇÃo: O DESDObRAMENTO DAS RELAÇÕeS DE TRABALHO}

O conceito de parasubordinazione $e^{2}$ tem origem no Código de Processo Civil Italiano, ${ }^{3}$ não possuindo tipificação na legislação pátria.

Em linhas gerais, os trabalhadores parassubordinados são aqueles que, resguardando certa hipossuficiência e dependência econômica em relação ao tomador de serviços, detém elevado grau de autonomia no modo de prestação de serviços, fugindo tanto ao conceito de trabalhador autônomo, quanto ao conceito de trabalhador subordinado.

Por certo que existem dois paradigmas já consolidados no que diz respeito à configuração do trabalhador em nosso país: o empregado - aquele que preenche, concomitantemente, os elementos fáticos jurídicos da relação de emprego ${ }^{4}$ - e o autônomo, trabalhador que define o modo de prestação de seus serviços, sem que seja subordinado pelo tomador, assumindo, por conseguinte, os riscos inerentes à sua atividade.

Em artigo publicado na obra "Parassubordinação: Homenagem ao Professor Márcio Túlio Viana", Juliana Augusto Medeiro de Barros assevera que:

\footnotetext{
"Outra situação bem mais complexa, se dá quando a relação de trabalho do prestador de serviços apresenta elementos não muito bem traçados, obscuros, que fazem com que o aplicador do direito tenha dúvidas no tocante ao enquadramento da relação jurídica em apreço na relação de emprego, mais protetiva, ou na relação de trabalho autônomo. É a chamada "zona grise", zona cinzenta em que se encontram diversos tipos de trabalhadores.” (2011, p.133).
}

\footnotetext{
2 Parassubordinação.

Para a doutrina, o surgimento da parassubordinação foi com o disposto no artigo 409, inciso III, do Código de Processo Civil Italiano, In Verbis:

"art. 409. Controversie Individuali di Lavoro:

[1] Si osservano le disposizioni Del presente capo nelle controversie relative a:

(...)

3) rapporti di agenzia, di rappresentanza commerciale ed altri rapporti di collaborazione Che si concretino in uma prestazione di opera continuativa e coordinata, prevalentemente anche se non a carattere subordinato."

Esses elementos são aqueles previstos nos artigos $2^{\circ}$ e $3^{\circ}$ da CLT, quais sejam: trabalho prestado por pessoa física, com pessoalidade, de forma não eventual, com onerosidade e sob a subordinação jurídica em face do empregador.
} 
Inobstante a falta de legislação que regule o tema, a jurisprudência brasileira é ainda controvertida ao decidir sob o reconhecimento, ou não, do vínculo empregatício do parassubordinado.

Todavia, a configuração do vínculo empregatício do parassubordinado, por certo, é a melhor medida a ser conferida pelo intérprete da lei, haja vista que entendimento contrário se dá no sentido do descumprimento da função social da empresa, que passaria a uma modalidade vulgarmente conceituada como "fantasma", por produzir sem empregados. ${ }^{5}$

A limitação contratual à autonomia da vontade do trabalhador parassubordinado existe, ainda que menos abrangente do que aquela presente na subordinação clássica. Todavia, os trabalhadores denominados parassubordinados, devido à natureza do serviço prestado, possuem menor dependência em relação ao poder de direção do empregador exercendo, normalmente, cargos de direção/coordenação, ou outras funções que demandem elevada capacitação técnica e intelectual.

Compreendidos esses aspectos, tem-se que a figura do trabalhador parassubordinado se aproxima daquele que, ajustado ao conceito de subordinação clássica, ocupa cargo de confiança.

Nesse sentido, vale transcrever excerto do acórdão da lavra da Juíza do Trabalho Adriana Goulart de Sena, enquanto convocada para atuação em segunda instância, nos autos do Processo n ${ }^{\circ}$ 00344-2000-110-03-00-6 RO, do Tribunal Regional do Trabalho da $3^{\text {a }}$ Região, publicado no dia 13.03.2001, in verbis:

\begin{abstract}
"Importa salientar que na função de confiança o empregado estabelece relação de mediatidade com a atividade material do emprego e a de imediatidade em relação aos demais empregados, que lhe estão subordinados, através daquilo que, como coordenação e organização do trabalho envolve critérios intelectuais mais apurados de racionalização da atividade de cada seção ou estabelecimento(...) A função de confiança é eminentemente hierárquica, no sentido de que o empregado, como chefe, como gerente ou como diretor, teve investida sua atividade de poderes que a ordem jurídica trabalhista confere, em princípio e por definição, ao empregador. Verifica-se na função de confiança a atração, para a pessoa do empregado que a exerce, de elementos inerentes e peculiares à titularidade do empregador, o que se explica pela trasladação, pela complexidade e pelo vulto da atividade econômica empresária."
\end{abstract}

Com esteio na hermenêutica constitucional evolutiva, a melhor interpretação a ser concedida ao artigo $7^{\circ}$ da Constituição Federal, se dá no sentido de sua aplicabilidade aos trabalhadores parassubordinados, observadas as especificidades desta relação de trabalho.

\footnotetext{
$5 \quad$ Neste sentido, o voto de autoria do Desembargador Relator Luiz Otávio Linhares Renault nos autos do processo de $n^{\circ}$ 00845-2009-105-03-00-5, 4a Turma, do Tribunal Regional do Trabalho da $3^{\text {a }}$ Região/MG, publicado no DEJT 9.11.2009.
} 
Nesta seara, Juliana Augusto Medeiro de Barros, ensina que:

\begin{abstract}
"A cada tipo de trabalhador são aplicáveis determinados direitos, de acordo com as peculiaridades da relação de trabalho em que são partes, entre elas, o grau de dependência econômica desses trabalhadores em relação ao tomador de serviços, o grau de inserção na atividade produtiva, a existência de subordinação jurídica do empregado ou de coordenação entre as partes, o local de prestação dos serviços e as condições em que o trabalho é exercido.” (2011, p. 142).
\end{abstract}

Independentemente das formas e adjetivações concedidas ao trabalho do homem, deverá o aplicador da lei interpretá-la teleologicamente, de modo a garantir a eficácia dos direitos e garantias fundamentais comuns a todo e qualquer grupo de trabalhadores.

\title{
3 - A APLICAÇÃO DA ARBITRAGEM NO DIREITO INDIVIDUAL DO TRABALHO: LIMITES E POSSIBILIDADES
}

Baseada na ampla negociação e liberdade de escolha do direito e do julgador pelos próprios litigantes, a arbitragem prestigiou, de forma expressa, o princípio da autonomia da vontade das partes.

Carlos Alberto Carmona conceitua este método heterocompositivo da seguinte forma:

\footnotetext{
A arbitragem é uma técnica para a solução de controvérsias através da intervenção de uma ou mais pessoas que recebem seus poderes de uma convenção privada, decidindo com base nesta convenção sem intervenção do Estado, sendo a decisão destinada a assumir eficácia de sentença judicial. (2009, p. 15).
}

Registre-se, contudo, que embora as partes possuam ampla liberdade de negociação e estipulação dos critérios de condução do procedimento arbitral, elas estarão limitadas aos bons costumes e à ordem pública, conforme se depreende da leitura do $\S 1^{\circ}$, artigo $2^{\circ}$, da Lei 9.307/96.

Outrossim, importante salientar que a submissão da resolução de eventuais litígios ao juízo arbitral somente será possível caso haja o comum acordo entre as partes interessadas.

Nos contratos de adesão existem procedimentos específicos a serem observados para a instauração da cláusula compromissória, de modo a assegurar a livre e espontânea escolha do aderente hipossuficiente e economicamente em desvantagem, in casu, o trabalhador. 
Estabeleceu o legislador que a validade da cláusula compromissória, nestes pactos, só terá a devida eficácia se o aderente tomar a iniciativa de instituir a arbitragem ou concordar expressamente com a sua instituição, desde que por escrito em documento anexo ou em negrito, com a assinatura ou visto especialmente para esta cláusula - inteligência do artigo $4^{\circ}$, $\S 2^{\circ}$, da Lei de Arbitragem.

Ao abordar a temática da arbitragem no processo trabalhista é preciso ficar atento às controvérsias existentes neste aspecto. Nos termos do art. $1^{\circ}$ da Lei. 9.307/96, somente as pessoas capazes de contratar poderão valer-se da arbitragem para dirimir litígios relativos a direitos patrimoniais disponíveis. Neste norte é importante registrar as diferenças na divisão doutrinária existente entre o direito coletivo e o individual do trabalho.

Para Alice Monteiro de Barros:

\begin{abstract}
"O direito individual tem como núcleo o contrato, que por sua vez cria uma relação individual de trabalho, cujos interesses são concretos, referindo-se a cada indivíduo determinado, enquanto o direito coletivo pressupõe uma relação coletiva de trabalho, em que os sujeitos se encontrem em função de uma coletividade profissional; logo, a relação jurídica daí advinda põe em jogo interesses abstratos de um grupo.” (2010, p. 1219).
\end{abstract}

No mesmo sentido, Maurício Godinho Delgado ensina que: "O direito individual do trabalho trata da regulação do contrato de emprego, fixando direitos, obrigações e deveres das partes." (2007, p. 1279). O autor se refere ao direito coletivo do trabalho como sendo aquele que "regula às relações inerentes à chamada autonomia privada coletiva, isto é, relações entre organizações coletivas de empregados e empregadores (...).” (2014, p. 1279).

Neste diapasão, no que se relaciona à seara do direito individual do trabalho, o posicionamento doutrinário e jurisprudencial majoritário vai de encontro à aplicabilidade do instituto da arbitragem, haja vista a indisponibilidade que precede a maioria dos direitos trabalhistas.

Registra-se, por oportuno, que a recente Lei 13.129/15, ampliou o âmbito de utilização da arbitragem ${ }^{6}$, sem acrescentar, contudo, a possibilidade de utilização deste referido instituto na seara laboral.

Mauro Schiavi, contudo, defende a possibilidade de aceitação, pelo trabalhador, de uma convenção arbitral, somente quando estiver rompida a relação de emprego, tendo em vista que o estado de sujeição do empregado impede sua livre manifestação de vontade em

\begin{tabular}{l}
\hline 6 Vide exemplo do artigo $1^{\text {a }}$, inciso $\S 1^{\mathrm{o}}$, que acrescentou a possibilidade de utilização da arbitragem \\
pela administração pública direta e indireta para dirimir conflitos relativos a direitos patrimoniais disponíveis.
\end{tabular} 
aceitar uma cláusula compromissória de arbitragem antes e durante a vigência do pacto laboral (SCHIAVI, p. 9).

Nesse sentido foi o voto condutor do Ministro Barros Levenhagen, do Tribunal Superior do Trabalho, em sede de recurso de revista ( $4^{a}$ turma, processo $n^{\circ}$ TST-RR-14430080.2005.5.02.0040.15.12.2010), do qual vale transcrever a seguinte passagem:

\begin{abstract}
"Diferentemente dessas situações contemporâneas à contratação do empregado e à vigência da pactuação, cabe destacar que, após a dissolução do contrato de trabalho, acha-se minimizada a sua vulnerabilidade oriunda da sua hipossuficiência econômico-financeira, na medida em que se esgarçam significativamente os laços de dependência e subordinação do trabalhador face àquele que o pretenda admitir ou que já o tenha admitido, cujos direitos trabalhistas, por conta da sua patrimonialidade, passam a ostentar relativa disponibilidade. Desse modo, não se depara, previamente, com nenhum óbice intransponível para que exempregado e ex-empregador possam eleger a via arbitral para solucionar conflitos trabalhistas, provenientes do extinto contrato de trabalho, desde que essa opção seja manifestada em clima de ampla liberdade, reservado o acesso ao Judiciário para dirimir possível controvérsia sobre a higidez da manifestação volitiva do ex-trabalhador, na esteira do artigo $5^{\circ}$, inciso XXXV da Constituição."
\end{abstract}

Já nos dissídios coletivos, diferentemente da corrente prevalecente no âmbito individual, o constituinte originário reconheceu expressamente a possibilidade de utilização do método arbitral como meio alternativo de solução dos litígios, embora não exista uma tradição cultural nacional na utilização de tal instituto - diversamente do que ocorre em nações de tradição anglo-saxônica (SCHIAVI, p.3)

Nos termos do $\S 2^{\circ}$, do art. 114, da Constituição Federal, quando qualquer das partes recusarem à negociação coletiva ou à arbitragem, será facultado às mesmas, de comum acordo, ajuizar dissídio coletivo de natureza econômica, cabendo à Justiça do Trabalho decidir o conflito, respeitada as disposições mínimas legais de proteção ao trabalho, bem como convencionadas anteriormente.

Por certo, no direito coletivo trabalhista, além de o âmbito de disponibilidade de direitos ser maior, o campo para debate e resolução de controvérsias faz com que seja plenamente útil a aplicação da arbitragem, mormente ante a existência de partes- os sindicatos- que se encontram em paridade de condições para debaterem e discutirem sobre o litígio em questão.

Urge registrar, todavia, que mesmo no campo do direito individual há grande cizânia doutrinária acerca de quais direitos são dotados de disponibilidade e quais o são de indisponibilidade.

A propósito, a lição de Hugo Gueiros Bernardes.verbis: 


\begin{abstract}
"a incerteza quanto ao direito (res dubia) é que permite a aparente 'renúncia parcial': não é renúncia parcial, mas transação apenas, pois a transação é negócio jurídico que, incidindo sobre a res dubia, é objetivamente justa a partir do livre consentimento. O problema está em a transação não incidir sobre res dubia, mas sobre direito líquido e certo, quando então será nula porque diminutiva ou renunciatória, vale dizer, porque uma falsa transação, nula por ilicitude do objeto. Nas inumeráveis 'conciliações' da Justiça do Trabalho, pratica-se muita transação diminutiva ou renunciatória, cuja nulidade não transparece, seja por causa da chancela judicial, seja porque o 'costume' vai legitimando essa redução de direitos sob a égide do poder judicial".
\end{abstract}

Ademais, a manifestação de negociação proveniente da autonomia privada, far-se-á presente nas relações juslaborais, embora, de forma limitada quando comparada ao paradigma civilista.

Não se pode perder de vistas que, a indisponibilidade dos direitos trabalhistas, possui dimensões e proporções diferenciadas, sendo, em alguns casos, absoluta, já em outros, relativa.

Sobre a distinção mencionada relativa às extensões da indisponibilidade, anota-se que, será absoluta quando: "o direito enfocado merecer uma tutela de interesse público, por traduzir um patamar civilizatório mínimo firmado pela sociedade política em um dado momento histórico". (DELGADO, 2014, p.214).

Noutro giro, será relativa quando: "o direito enfocado traduzir interesse individual ou bilateral simples, que não caracterize um padrão civilizatório geral mínimo firmado pela sociedade política em um dado momento histórico". (DELGADO, 2014, p.215). O mesmo autor exemplifica quanto àquela, o direito à assinatura de CTPS e o salário mínimo e, quanto a esta, a modalidade de salário paga ao empregado ao longo da relação de emprego (salário fixo versus salário variável, ilustrativamente).

Apesar de grande parte das normas trabalhistas possuírem conteúdo indisponível há aquelas dotadas de total disponibilidade.

Incorporar a possibilidade de utilização da arbitragem no âmbito do direito individual do trabalho- com a atenção e precaução necessária- como forma de promover a pacificação social e a realização da justiça deve ser medida a ser aceita e incorporada socialmente.

Neste sentido, o seguinte julgado da Justiça do Trabalho:

JUÍZO ARBITRAL - DISSÍDIO INDIVIDUAL TRABALHISTA - COISA JULGADA RELATIVIZAÇÃO - A norma expressa no art. 31 da Lei 9.307/96 determina, in verbis: "[...] A sentença arbitral produz, entre as partes e seus sucessores, os mesmos efeitos da sentença proferida pelos órgãos do Poder Judiciário e, sendo condenatória, constitui título executivo". A própria lei estabelece o status de título executivo extrajudicial à sentença arbitral (art. 31 da Lei 9.307/96). E ainda, extingue-se o processo sem resolução de mérito pela convenção de arbitragem, segundo o inciso IX do art. 267 do CPC, introduzido pelo art. 41 da Lei 9.307/96. Não há dúvida de que, no âmbito trabalhista, a possibilidade de as 


\begin{abstract}
partes recorrerem ao juízo arbitral está expressamente prevista para a solução de conflitos coletivos, nos termos do $\S 2^{\circ}$ do art. 114 da Constituição. Além disso, está prevista na Lei de Greve e de PLR. Tudo muito bem dito e colocado no ordenamento jurídico. Assim, o instituto da arbitragem não deve ser desprezado, desde que não implique denegação da justiça. Cumpridas todas as exigências legais, e desde que respeitadas as garantias mínimas previstas no ordenamento jurídico trabalhista, é possível a solução dos conflitos individuais trabalhistas pela utilização da arbitragem quando se tratar de direito patrimonial disponível. Cabe ao Poder Judiciário, inclusive o Trabalhista dar o valor que entender devido ao juízo arbitral, como equivalente jurisdicional de solução dos conflitos. Não há como ignorar institutos jurídicos que surgem da real necessidade de resolução de conflitos dos próprios atores sociais. Por outro lado, exige-se cautela de tal forma que a arbitragem não se transforme em um meio de burlar os princípios e leis trabalhistas, ou ainda, em um desvio da natureza do instituto cuja essência é de solução de conflitos. Lembro que a relativização da coisa julgada é amplamente aplicada em nosso ordenamento jurídico, encontrando campo fértil em se tratando de conferir validade ao juízo arbitral, quando e se for o caso. Neste contexto, a validade do juízo arbitral passa pela análise do cumprimento dos requisitos legais, notadamente, de se tratar de direitos patrimoniais disponíveis com clareza e transparência em torno do objeto litigioso, não existindo vício de vontade por parte do contratante, dentre outros. Não há ofensa ao princípio da inafastabilidade da Jurisdição (art. $5^{\circ}$, inc. XXXV, da Constituição) na medida em que o Judiciário continua com o controle da legalidade do ato. (TRT da $3^{\mathrm{a}}$ Região, $4^{\mathrm{a}}$ Turma, Relatora Juíza Convocada Ana Maria Amorim Reboucas, DEJT/TRT3/Cad.Jud. Página 206, 10/10/2014).
\end{abstract}

A propósito, cumpre registrar que, a indisponibilidade dos direitos trabalhistas, reflexo de seu basilar princípio da proteção, deve ser observada, também, nos conflitos envolvendo empregados parassubordinados. Isto porque se por um lado, esse conceito visa à manutenção das garantias mínimas do empregado, por outro, tais garantias sequer foram obtidas pelo trabalhador parassubordinado, representando, pois, a arbitragem, uma possibilidade para a ampliação de seus direitos.

Em sua obra clássica sobre os princípios do direito do Trabalho, o jurista uruguaio Plá Rodrigues já preconizava que:

\begin{abstract}
"No campo do Direito do Trabalho, surge, pois, uma distinção essencial e de suma importância: nele existem normas imperativas que não excluem a vontade privada, mas a cercam de garantias para assegurar sua livre formação e manifestação, valorizando-a como a expressão da própria personalidade humana. Ressalte-se que o Direito do Trabalho não é, no fundo, um direito obrigacional. Antes de mais nada, é direito entre pessoas, distinguindo-se não obstante do direito de família pelo grau de intensidade das relações pessoais, bem como pelo caráter temporário e precariedade dos laços pessoais. Um direito que em sua essência disciplina a conduta humana em função criadora de valores, que é a expressão da responsabilidade social e da colaboração para um fim comum, não pode excluir de seu campo a manifestação da vontade privada, mas, pelo contrário, deve traçar-lhes limites que permitam o cumprimento de sua missão"
\end{abstract}

Em suma, tudo isso se põe para se demonstrar que, ainda que se identifique, com certa dificuldade, a indisponibilidade da maior parte dos direitos trabalhistas dos empregados subordinados, em razão das características peculiares dos trabalhadores (rectius: empregados) 
parassubordinados, haverá, por certo, diferenciação entre referida indisponibilidade para os empregados subordinados em relação aos parassubordinados.

Ademais, tanto o trabalhador parassubordinado quanto o subordinado, integram a lógica produtiva baseada no lucro ofertada pelo empregador. Há, apenas, a maior ou menor presença do controle e direção empresarial na relação com referidos trabalhadores.Neste cenário, respeitada as nuances de cada relação trabalhista, imprescindível observar que para que haja a devida utilização do procedimento arbitral nos contratos individuais dos empregados parassubordinados, o próprio Direito do Trabalho deve se encaminhar no sentido de se adaptar e absorver referida categoria de trabalhadores.

Veja-se que para Luiz Carlos Amorim Robortella: "No que concerne a determinados trabalhadores de alto nível, como executivos, diretores de sociedades, gerentes ou de grande especialização, com (...) intensa autonomia e poder, parece-nos perfeitamente admissível a convenção particular de arbitragem". E como demonstrado em alhures, os empregados parassubordinados, podem ser situados em posição jurídica semelhante a estes altos empregados.

Como explica Otávio Pinto e Silva (2002, p. 196), interessante anotar que o ordenamento jurídico italiano aborda a questão dos trabalhadores parassubordinados, estabelecendo seu conceito e campo de abrangência bem como, no campo processual, submetendo-os às mesmas regras previstas para os empregados subordinados (art. 409, n. 3 do Codice di Procedure Civile $^{7}$ ). Todavia, é de se ressalvar que naquele ordenamento há previsão da realização de arbitragem no processo trabalhista, perante uma espécie de comissão de conciliação prévia (que não obstante a nomenclatura também tem funções arbitrais), cujo laudo tem força de sentença, contra o qual a parte pode recorrer no prazo de 30 dias após os quais passa a ter força executiva plena. ${ }^{8}$

$7 \quad$ Art. 409. (Controversie individuali di lavoro)

Si osservano le disposizioni del presente capo nelle controversie relative a:

(...)

3) rapporti di agenzia, di rappresentanza commerciale ed altri rapporti di collaborazione che si concretino in una prestazione di opera continuativa e coordinata, prevalentemente personale, anche se non a carattere subordinato.

$8 \quad$ Art. 412.

(Risoluzione arbitrale della controversia)

In qualunque fase del tentativo di conciliazione, o al suo termine in caso di mancata riuscita, le parti possono indicare la soluzione, anche parziale, sulla quale concordano, riconoscendo, quando $e^{\prime}$ possibile, il credito che spetta al lavoratore, e possono accordarsi per la risoluzione della lite, affidando alla commissione di conciliazione il mandato a risolvere in via arbitrale la controversia.

Nel conferire il mandato per la risoluzione arbitrale della controversia, le parti devono indicare:

1) il termine per l'emanazione del lodo, che non può comunque superare $i$ sessanta giorni dal conferimento del mandato, spirato il quale l'incarico deve intendersi revocato; 
Ao se analisar, por exemplo, as disposições da legislação laboral acerca dos trabalhadores - subordinados - que ocupam cargos de gerência, diretoria e chefia de departamento, percebe-se que, a princípio, estes não fazem jus ao adicional noturno, as horasextras e demais direitos aplicáveis a outras categorias trabalhistas acerca da jornada de trabalho, nos termos do artigo 62, inciso II, do Texto Consolidado em confronto com o disposto no artigo $7^{\circ}$, incisos IX e XIII, da Constituição. Trata-se, isso sim, de uma certa mitigação à subordinação clássica que justifica, tanbém no campo processual, uma maior autonomia desse tipo de empregado para valer-se de meios alternativos de resolução do conflito como a arbitragem.

Nesse sentido, a possibilidade de discussão para a obtenção de tais garantias pelo trabalhador parassubordinado, que normalmente ocupa cargos similares, via procedimento arbitral, mostra-se como um avanço do caro aspecto protetivo do Direito do Trabalho.

Vale, evidentemente, anotar que a arbitragem não se constitui no "remédio para todos os males", como informa PAMPLONA FILHO (2004). Reconhece-se, isso sim, a existência de dificuldades de sua aplicação, principalmente no campo jus laboral, em decorrência inclusive dos custos envolvidos e da falta de uma "cultura arbitral".

Todavia, malgrado não se tratar da tal almejada (e utópica) panacéia que se busca no campo processual como um todo, esse método de resolução alternativa de conflitos merece uma melhor análise pela doutrina e jurisprudência trabalhista, principalmente quando presentes, no caso, peculiaridades que permitam inferir uma maior autonomia por parte empregado, reveladora de uma desnecessária aplicação intransigente do princípio da proteção.

2) le norme invocate dalle parti a sostegno delle loro pretese e l'eventuale richiesta di decidere secondo equità, nel rispetto dei principi generali dell'ordinamento e dei principi regolatori della materia, anche derivanti da obblighi comunitari.

Il lodo emanato a conclusione dell'arbitrato, sottoscritto dagli arbitri e autenticato, produce tra le parti gli effetti di cui all'articolo 1372 e all'articolo 2113, quarto comma, del codice civile.

Il lodo è impugnabile ai sensi dell'articolo 808-ter. Sulle controversie aventi ad oggetto la validità del lodo arbitrale irrituale, ai sensi dell'articolo 808-ter, decide in unico grado il tribunale, in funzione di giudice del lavoro, nella cui circoscrizione è la sede dell'arbitrato. Il ricorso è depositato entro il termine di trenta giorni dalla notificazione del lodo. Decorso tale termine, o se le parti hanno comunque dichiarato per iscritto di accettare la decisione arbitrale, ovverso se il ricorso è stato respinto dal tribunale, il lodo è depositato nella cancelleria del tribunale nella cui circoscrizione è la sede dell'arbitrato. Il giudice, su istanza della parte interessata, accertata la regolarità formale del lodo arbitrale, lo dichiara esecutivo con decreto. 


\section{CONCLUSÃO}

O Direito do Trabalho brasileiro reconhece a autonomia negocial do trabalhador, indicando ser o ramo justrabalhista campo frutífero para a possibilidade de uso do instituto arbitral, desde que seja respeitado o princípio último de proteção ao trabalhador.

Sabe-se que o Estado encontra-se afastado das necessidades mais urgentes do mundo trabalhista, devendo cumprir papel de estabelecer condições mínimas, mas não definitivas, para garantir a dignidade da pessoa do trabalhador. Definir, taxativamente, quais são os direitos do obreiro, muitas vezes impede que discussões maiores sobre a ampliação dos mesmos direitos ocorram.

O trabalhador parassubordinado, desamparado pela legislação trabalhista e pela Justiça do Trabalho que ainda reluta em reconhecer o vínculo empregatício de tal relação, encontra na arbitragem a alternativa de avultar os seus direitos.

O procedimento arbitral, sendo sigiloso, mostra-se pertinente tanto às empresas que prezam pela não exposição dos conflitos trabalhistas nos quais estão envolvidas, quanto aos trabalhadores que, muitas vezes, sentem-se compelidos a não acionar Justiça do Trabalho, temendo serem alvos de futuras retaliações.

O fato dos contratos do trabalhador parassubordinado, normalmente, possuírem valores mais elevados é outro ponto favorável à aplicação do instituto arbitral que é indicado, precipuamente, para contratos dessa natureza.

Veja-se que no que diz respeito à delicada questão da disponibilidade/transacionabilidade dos direitos trabalhistas, é prudente que se faça uma interpretação finalista de tal princípio, já que, não existindo no ordenamento pátrio as garantias mínimas ao trabalhador parassubordinado, trazer à baila garantias tidas como indisponíveis - para o trabalhador subordinado (jornada de trabalho, horas-extras, adicional noturno, por exemplo) - significa, em verdade, viabilizar a possibilidade de negociação para a aquisição de tais direitos para aqueles cuja prestação de serviço caracterize a parassubordinação.

Logo, resta por bem concluir pela possibilidade de utilização da arbitragem nos conflitos trabalhistas individuais, em que se tenha como parte o empregado parassubordinado, dada as características peculiares desses trabalhadores, entendimento que atende a um só tempo os interesses de empregados e empregadores, bem como contribui para o alcance da tão almejada celeridade (e efetividade) processual. 


\section{REFERÊNCIAS}

BARROS, Alice Monteiro de. Curso de Direito do Trabalho. $2^{\text {a }}$ ed. São Paulo: LTr, 2006.

BERNARDES, Hugo Gueiros. Direito do Trabalho. V.1. São Paulo: LTr, 1989.

BRASIL. Lei $\mathbf{n}^{0} 5.452$ de $1^{\circ}$ de maio de 1943. Aprova a Consolidação das Leis do Trabalho. Vade Mecum acadêmico de direito. 11ª . ed. São Paulo: Rideel, 2012.

BRASIL. Constituição (1988). Constituição da República Federativa do Brasil: Promulgada em 5 de outubro de 1988. Brasília: Senado Federal.

BRASIL. Tribunal Regional do Trabalho da $3^{\text {a }}$ Região. Processo:RO 00344-2000-110-03-006. Relatora Adriana Goulart de Sena. Belo Horizonte, 13 de março de 2001. Disponível em: <http://www.trt3.jus.br>. Acesso em 10.12.2014.

BRASIL. Tribunal Regional do Trabalho da 3ª Região. Processo:RO 00915-2013-135-03-003. Relatora Ana Maria Amorim Rebouças. Belo Horizonte, 10 de outubro de 2014. Disponível em: <http://www.trt3.jus.br>. Acesso em 10.12.2014.

BRASIL. Tribunal Regional do Trabalho da $3^{\mathrm{a}}$ Região. Processo: RO no 00845-2009-105-0300-5. Relator Luiz Otavio Linhares Renault. Belo Horizonte, 09 de novembro de 2009. Disponível em: <http://www.trt3.jus.br>. Acesso em 10.12.2014.

BRASIL. Tribunal Superior do Trabalho. Processo: 144300-80.2005.5.02.0040. Relator: Ministro Barros Levenhagen. Brasília, 15 de dezembro de 2010. Disponível em <www.tst.jus.br>. Acesso em 13.08.2015.

CARMONA, Carlos Alberto. Arbitragem e processo: Um comentário à Lei $\mathbf{n}^{\mathbf{0}}$ 9.307/96. São Paulo: Atlas. 2009

DELGADO, Mauricio Godinho. Curso de Direito do Trabalho. 13 a ed. São Paulo: LTr, 2014.

MARIANO, Jane Vargas. Subordinação estrutural: uma forma de minimizar a precarização das relações de trabalho oriundas da terceirização. Jus Navigandi, Teresina, ano 16, n. 3088, 5.dez.2011. Disponível em:<http://jus.com.br/revista/texto/20675>. Acesso em: 23 dez. 2014.

MENDES, Marcus Menezes Barberino; CHAVES JÚNIOR, José Eduardo de Resende. Subordinação estrutural-reticular. Uma perspectiva sobre a segurança jurídica. Jus Navigandi, Teresina, ano 13, n. 2005, 27.dez.2008. Disponível em: <http://jus.com.br/revista/texto/12126>. Acesso em: 22 dez. 2014.

PAMPLONA FILHO, Rodolfo. Atualizando uma visão didática da arbitragem na área trabalhista. Disponível em: http://jus2.uol.com.br/doutrina/texto.asp?id=6831>. Acesso em: 15.ago.2015.

PLÁ RODRIGUEZ, Américo. Princípios de Direito do Trabalho. 3.ed. São Paulo: LTr, 2000, p. 151. 
SCHIAVI, Mauro. Aspectos Polêmicos e Atuais da Arbitragem como Meio de Solução dos Conflitos Trabalhistas. Disponível em: http://cursos.lacier.com.br/artigos/periodicos/Aspectos\%20polemicos\%20e\%20atuais\%20da $\% 20$ arbitragem\%20no\%20Processo\%20do\%20Trabalho.pdf. Acesso em 10 de julho de 2015.

RENAUlT, Luiz Otávio Linhares. Parassubordinação: Homenagem ao Professor Márcio Túlio Viana. Coord. Luiz Otávio Linhares Renault, Paula Oliveira Cantelli, Lorena Vasconcelos Porto e Fernanda Nigri. São Paulo: LTr, 2011.

ROBORTELLA, Luiz Carlos Amorim. Solução extrajudicial dos conflitos do trabalho. In: Revista Trabalho \& Doutrina n. 14, São Paulo: Saraiva, 1997.

SILVA, Otávio Pinto e. Subordinação, Autonomia e Parassubordinação nas Relações de Trabalho. São Paulo: LTr, 2004. 